\title{
Juvenile victimisation in a group of young Sri Lankan adults
}

\author{
Aswini D Fernando ${ }^{1}$ and Wasantha Karunasekera ${ }^{1}$ \\ (Index words: juvenile victimisation, child maltreatment, Sri Lanka)
}

\begin{abstract}
Objective To study the prevalence of juvenile victimisation in a group of young adults.

Method A juvenile victimisation questionnaire was distributed among 1322 Sri Lankan undergraduates. The questionnaire consisted of different modules (child maltreatment, conventional crime, peer-sibling victimisation, indirect victimisation, introduction to substances and parental deprivation).
\end{abstract}

Results The response rate was $90 \%$. The mean age of the cohort was 21.8 years. $59 \%$ were females. $44 \%$ and $36 \%$ had experienced sexual and physical maltreatment respectively. In both categories males were affected more than females $(p<0.001)$. Physical abuse had commonly taken place at school (51\%) and home (40\%). Witnessing violence at home was the highest form of indirect victimisation (66\%). 10\% were introduced to substances in childhood. Usage of substances (cigarettes, alcohol and drugs) was significantly higher in children whose fathers used substances compared to children whose fathers did not $(p<0.001)$.

Conclusion Many children in Sri Lanka are exposed to victimisation. They seem to suffer these in the very environments that should be nurturing and protecting them.

\section{Introduction}

Victimisation during childhood occurs in different forms. Children experience these events in silence, often not realising that they are being victimised. It is often in retrospect, in adulthood, that they realise they had been victimised. These childhood experiences, during the formative years, have a lasting impact on the individual's life and achievements [1]. The incidence of such events amongst Sri Lankan children is not known. Some hospital and community based data show that the occurrence of victimisation is not rare [2,3]. The child victims that come to hospital are usually the severely affected, and could be the "tip of the iceberg". The available data deals with incidents of child maltreatment. However, there are other forms of victimisation, that if left unrecognised, could have effects on the child reaching full developmental potential. We carried out this study to assess the prevalence of maltreatment and other types of victimisation experienced during childhood.

\section{Methods}

A questionnaire was administered to 1322 undergraduates of the University of Kelaniya in the first and second years of their university career. Students from 5 faculties of the university participated in the study. They were from the Faculties of Commerce (62\%), Medicine (26\%), Science (8\%), Humanities (2\%) and Social Sciences (2\%). In order to ensure seating arrangements conducive to reporting confidential and sensitive events, the questionnaire was administered at the end of examinations held in different faculties. This contributed to the variation in representation. The participants were requested to divulge details of victimisation experienced in childhood (up to 18 years).

The questionnaire was based on the juvenile victimisation questionnaire (JVQ) for estimation of the incidence of victimisation in childhood [4]. The questionnaire was translated into Sinhala (local dialect) and back translated. It was pre-tested among 45 medical students of the University of Kelaniya.

To improve the content validity of the questionnaire two additional modules were included in addition to the 4 modules in the original JVQ i.e. child maltreatment, conventional crime, peer and sibling victimisation and witnessing violence and other types of indirect victimisation. The additional modules were the introduction to substances in childhood and parental deprivation (these have not been addressed in the Sri Lankan setting). The questionnaire was modified to make some of the terminology comprehensible to a Sri Lankan population and to ensure that the questions were culturally and socially acceptable. The participants were given the choice of answering the questionnaire either in English or in Sinhala. Data analysis was performed using Epi info version 6. Approval for the study was obtained from the Ethics Committee, Faculty of Medicine, University of Kelaniya.

\section{Results}

The response rate was $90 \%(1189 / 1322)$. The mean age of the cohort was 21.8 years, and $59 \%$ were females. The prevalence of different types of victimisation are given in table 1 . Table 2 describes the different types of sexual maltreatment. Table 3 describes the characteristics of physical maltreatment.

${ }^{1}$ Department of Paediatrics, Faculty of Medicine, University of Kelaniya, Sri Lanka.

Correspondence: ADF, e-mail <aswini@sltnet.lk>. Received 9 January and revised version accepted 6 May 2009. Competing interests: none declared. 
Table 1. Prevalence and sex distribution of different types of victimisation

\begin{tabular}{|c|c|c|c|c|c|c|c|}
\hline \multirow[t]{2}{*}{ Module } & \multicolumn{2}{|c|}{ Total } & \multicolumn{2}{|c|}{ Male } & \multicolumn{2}{|c|}{ Female } & \multirow[t]{2}{*}{$p$ value } \\
\hline & $N$ & $\%$ & $N$ & $\%$ & $N$ & $\%$ & \\
\hline
\end{tabular}

\section{Child maltreatment}

Sexual

Physical

Bias attacks

Emotional

Neglect

$\begin{array}{lllllll}519 & 44 & 282 & 58 & 237 & 34 & <0.001 \\ 427 & 36 & 206 & 43 & 221 & 31 & <0.001 \\ 333 & 28 & 161 & 33 & 172 & 24 & <0.001 \\ 119 & 10 & 51 & 11 & 68 & 10 & 0.7 \\ 27 & 02 & 12 & 02 & 15 & 02 & 0.8\end{array}$

\section{Conventional crime}

Experience of being robbed

Experience of attempted personal theft

$\begin{array}{lllllll}228 & 20 & 114 & 24 & 114 & 16 & 0.002 \\ 185 & 16 & 105 & 22 & 80 & 11 & <0.001 \\ 202 & 17 & 96 & 20 & 106 & 15 & 0.03 \\ 418 & 35 & 262 & 54 & 156 & 22 & <0.001\end{array}$

3. Peer and sibling victimisation

Assaulted by a sibling

$\begin{array}{lllllll}125 & 11 & 36 & 08 & 89 & 13 & 0.006 \\ 95 & 08 & 71 & 15 & 24 & 03 & <0.001 \\ 30 & 03 & 15 & 03 & 15 & 02 & 0.4 \\ 254 & 22 & 116 & 24 & 138 & 20 & 0.08\end{array}$

\section{Witnessing violence and indirect victimisation}

Witnessed domestic violence

$\begin{array}{lllllll}407 & 35 & 189 & 39 & 218 & 31 & 0.004\end{array}$

between parents

Witnessed parents assaulting siblings

$363 \quad 31$

14430

21931

0.7

*Witnessed assault with a weapon

$425 \quad 36$

21043

$215 \quad 30$

$<0.001$

*Witnessed assault without a weapon

$653 \quad 55$

$270 \quad 56$

$383 \quad 55$

0.6

5. Introduction to smoking, alcohol and drugs

11010

$98 \quad 20$

$12 \quad 02$

$<0.001$

\section{Parental deprivation}

Parental separation due to marriage break-up

$\begin{array}{lllllll}56 & 05 & 25 & 06 & 31 & 05 & 0.6 \\ 57 & 05 & 27 & 06 & 30 & 04 & 0.4\end{array}$

${ }^{*}$ Between family members and outsiders 
Table 2. Characteristics of sexual maltreatment

\begin{tabular}{|c|c|c|c|c|c|c|c|c|}
\hline \multirow[t]{2}{*}{ Types of sexual maltreatment } & \multirow{2}{*}{$\begin{array}{l}\text { Mean age } \\
\text { years }^{s}\end{array}$} & \multicolumn{2}{|c|}{ Total } & \multicolumn{2}{|c|}{ Male } & \multicolumn{2}{|c|}{ Female } & \multirow[t]{2}{*}{$p$ value } \\
\hline & & $N$ & $\%$ & $N$ & $\%$ & $N$ & $\%$ & \\
\hline \multicolumn{9}{|l|}{ 1. Fondling of genitalia } \\
\hline a. By known person & 11 & 121 & 11 & 65 & 13 & 56 & 08 & $<0.001$ \\
\hline b. Unknown person & 14.6 & 165 & 14 & 51 & 11 & 114 & 16 & 0.008 \\
\hline $\begin{array}{l}\text { 2. Did a child or teenager** } \\
\text { make you get involved in } \\
\text { sexual activities? }\end{array}$ & 15 & 53 & 05 & 44 & 09 & 09 & 01 & $<0.001$ \\
\hline 3. Sexual assault by an adult & 11.6 & 27 & 03 & 23 & 05 & 04 & 0.6 & $<0.001$ \\
\hline $\begin{array}{l}\text { 4. Sexual relationship with "consent" } \\
\text { with a person over } 18 \text { years }{ }^{\dagger}\end{array}$ & 14.9 & 27 & 03 & 26 & 05 & 01 & 01 & $<0.001$ \\
\hline 5. Exhibitionism & 14.5 & 205 & 18 & 61 & 13 & 144 & 20 & $<0.001$ \\
\hline $\begin{array}{l}\text { 6. Exposure to blue } \\
\text { films/pornography }\end{array}$ & 15.3 & 263 & 23 & 241 & 50 & 22 & 03 & $<0.001$ \\
\hline
\end{tabular}

**Person under 18 years - school boy/girl, friend, relative

+ Consent for sexual relationship is only possible after 16 years of age in Sri Lanka. There were only 2 individuals between $16-18$ years in the 27 that were affected. Others were under 16 years.

‡ $91 \%$ through a friend

$\S$ mean age for both sexes

Table 3. Characteristics of physical maltreatment of the recalled event

\begin{tabular}{|c|c|c|c|c|c|c|c|}
\hline \multirow{2}{*}{ Characteristics } & \multicolumn{2}{|c|}{ Total } & \multicolumn{2}{|c|}{ Male } & \multicolumn{2}{|c|}{ Female } & \multirow[t]{2}{*}{$p$ value } \\
\hline & $N$ & $\%$ & $N$ & $\%$ & $N$ & $\%$ & \\
\hline \multicolumn{8}{|c|}{ Age at exposure (years) } \\
\hline $3-4.9$ & 08 & 02 & 03 & 02 & 05 & 03 & 0.03 \\
\hline $5-9.9$ & 100 & 28 & 40 & 23 & 60 & 33 & \\
\hline $10-14.9$ & 147 & 41 & 72 & 40 & 75 & 41 & \\
\hline $15-18$ & 103 & 29 & 62 & 35 & 41 & 23 & \\
\hline \multicolumn{8}{|l|}{ Perpetrator } \\
\hline Teacher*** & 139 & 33 & 69 & 35 & 70 & 32 & 0.0006 \\
\hline Father & 55 & 14 & 19 & 10 & 36 & 16 & \\
\hline Mother & 30 & 07 & 08 & 04 & 22 & 10 & \\
\hline Friend & 50 & 12 & 35 & 18 & 15 & 07 & \\
\hline Older student & 34 & 08 & 20 & 10 & 14 & 06 & \\
\hline Other & 47 & 11 & 17 & 09 & 30 & 14 & \\
\hline More than one & 64 & 15 & 32 & 16 & 32 & 15 & \\
\hline \multicolumn{8}{|l|}{ Place of abuse } \\
\hline School & 204 & 51 & 120 & 62 & 84 & 41 & 0.001 \\
\hline Home & 157 & 40 & 57 & 30 & 100 & 49 & \\
\hline Other & 36 & 09 & 16 & 08 & 20 & 10 & \\
\hline
\end{tabular}

Modes used for corporal punishment were - stick (60\%), hand (27\%), kicking (2\%) and more than one mode in $11 \%$. There were no injuries noted in $74 \%$. 21\% had suffered a small cut/bruise, $2 \%$ a large cut/bruise and in $3 \%$ a combination of large and small cuts/bruises. 
In module 1 (child maltreatment), the commonest types of maltreatment experienced were sexual (44\%) and physical (36\%). The prevalence of both types of abuse was significantly higher in males than in females $(\mathrm{p}<0.001)$. Of those sexually abused, many had experienced exposure to pornographic films (23\%) and exhibitionism (18\%). 27\% had experienced one type of sexual maltreatment described in table 2 , while $11 \%$ and $6 \%$ had experienced two or more than two types of maltreatment respectively. The commonest perpetrators of physical maltreatment were teachers (33\%) and parents (father 14\%, mother 7\%). The common places at which such abuse took place were school (51\%) and home (40\%). The common reasons for bias attacks (table 1) in both males and females were related to self image (43\% and $45 \%$ ), family background (24\% and $23 \%$ ) and physical deformities (11\% and 14\%). $2 \%$ claimed that their parents had intentionally neglected their basic needs. The common areas of neglect were clothing (19\%), schooling (22\%) and food (15) \%.

In module 2, (conventional crime) attempted assault (36\%) and experience of being robbed (20\%) were the common categories. In module 3 (peer and sibling victimisation), the commonest event was bullying at the hands of peers and siblings (22\%). In module 4 (witnessing violence and other types of indirect victimisation), 35\% witnessed domestic violence between parents and 31\% witnessed parents assaulting siblings. In module 5 (introduction to substances) $10 \%$ had been introduced to smoking, alcohol and drugs during their childhood. The incidence was significantly higher in males than in females $(\mathrm{p}<0.001)$.

Amongst males 32\% had taken alcohol, 23\% cigarettes and 1\% drugs during their childhood (this information was not analysed amongst females as the number was very low). The age of introduction to substances for the first time (irrespective of gender) was between 16 -18 years (56\%), between $12-15$ years (36\%) and between 7-11 years (8\%). Overall use of substances by the father was $33 \%$. Use of substances was significantly higher in children whose fathers were using substances compared to children whose fathers did not $(\mathrm{p}<0.001)$. In module 6 (parental deprivation), $5 \%$ had experienced breakup of the marriages of their parents.

\section{Discussion}

The JVQ is a comprehensive questionnaire designed to gather information on a broad range of victimisations. It has been designed with sensitivity to language and content so that it could be administered to children as young as 12 years, while still being able to gather information regarding even statutory rape with its legal implications. It has been proved a good tool for the purpose of assisting professionals wanting a thorough record for assessment of victimisation and for research.

The prevalence of child maltreatment in different communities is difficult to compare as the definitions used by researchers vary. Therefore the JVQ is a good instrument to assess the epidemiology of the problem. It has been designed to be used as a self-administered questionnaire for children aged 12 years and above and as a caregiver proxy report for children below this age. Though it has been found to be acceptable to be administered to adults for retrospective reporting, caution is urged [5]. This is due to two reasons. Firstly, the original JVQ limits its responses to events that have occurred "in the last one year”. However, when administered to adults this has to be changed to "ever" to indicate experiences occurring at any time during childhood, and memory for some events, like robbery, are unlikely to be good after many years. Secondly, childhood referent periods make it impossible to compare rates for children of different ages. Despite these limitations we were compelled to use a cohort of young adults because the ethics committee did not permit administration of the questionnaire to school children. Undergraduates in the first and second years of study were selected. The study had a good response rate of $90 \%$.

The young adults in this cohort had experienced several types of victimisation. It is interesting to note that males had significantly more exposure to sexual and physical maltreatment and to bias attacks than females. Overall 44\% had experienced some form of sexual maltreatment (58\% males, 34\% females). This is contrary to hospital based data where the incidence of sexual and physical maltreatment is higher in females than in males [2]. Could this mean that males who are maltreated do not present for medical attention? Could males be accepting physical maltreatment as a norm and not reporting it? The reasons why more females are presenting to hospital may be social, in a society that is very protective of the female child and where female virginity is still much valued. If so, it is important to recognise this as silent acceptance of maltreatment by males may lead to psychological sequelae, as no medical or psychological help would be offered to them.

Of the study population, 36\% had experienced physical maltreatment. Once again males were significantly more affected than females (43\% vs 31\%). It is important to note that physical maltreatment occurred in the school and home environments in $91 \%$ of cases. These are the very environments that should be nurturing, and setting standards and examples to children. Corporal punishment in schools has been banned via a Ministry of Education circular in Sri Lanka since 2001 [6]. This circular may not have had much impact on this study cohort, as they had entered university in 2004. There does not seem to be any gender bias with regard to corporal punishment in schools by teachers (males 35\%, females 32\%). However, there is a significant female preponderance in physical maltreatment meted out at home by the mother (10\% vs $4 \%$ ) and father (16\% vs $10 \%)$.

Domestic violence was witnessed and experienced by $66 \%$ (violence between parents and parent assaulting 
a sibling). When children are exposed to environments where problems are solved with violence they naturally assume that the only way to solve problems is with violence. Improvement of parenting skills and alternative ways of settling differences of opinion are important strategies that need to be inculcated in society.

Children from broken families are at a higher risk of being victims of violence [2]. One of the reasons for these "broken" families in Sri Lanka is maternal employment abroad. 5\% of our cohort had experienced maternal separation during their childhood due to the mother being employed abroad.

Ten percent of participants in our study were exposed to substances during childhood. Use of substances was significantly higher in children whose fathers were using substances compared to children whose fathers were not. Parents and teachers should take heed of this, and be required to take necessary action to minimise such exposure to children at these impressionable ages. Parents should realise the importance of good role modeling.

Much evidence is available regarding the physical, psychological, behavioural, emotional and societal consequences of violence against children [1, 7]. Research has shown that prolonged exposure to violence perpetrated against them or witnessing violence has an effect on the developing brain which in turn leads to social, emotional and cognitive impairments as well as to behaviour that cause diseases, injury and social problems $[1,8]$. Other fallouts are obesity, early sexual activity, smoking and substance abuse [7, 8]. Related mental health problems include anxiety, depressive disorders, hallucinations, impaired work performance, memory disturbances, aggressive behaviour, intimate partner violence and suicide attempts [7, 8]. A strong graded relationship has been demonstrated between the breadth of exposure to abuse or household dysfunction during childhood and risk factors for leading causes of death in adults like ischaemic heart disease, cancer, chronic lung disease, skeletal fractures and liver disease [9].

We observed significant rates of childhood victimisation in a group of young adults in this country.
Our sample could be considered biased, and it would be interesting to note whether prevalence rates would be higher if the study was based in the community, of maltreatment as long term effects could have an effect on educational outcome. The education and health sectors, and community and religious leaders have a responsibility to increase awareness and develop strategies for prevention of this social ill.

\section{References}

1. Pinherio PS. World Report on Violence Against Childern. UN Secretary General's Study on Violence Against Children New York, 2006.

2. Fernando AD, Karunasekera KAW, Fernando L, Samarasekera A. Child abuse and neglect: who abuses them and who gets abused? (Abstract). Sri Lanka Medical Association, 2005: 30.

3. De Silva DGH. Child abuse: a manual for medical officers in Sri Lanka. Colombo, 2000.

4. Finkelhor D, Hamby SL, Ormrod R, Turner H. The juvenile victimisation questionnaire: reliability, validity and national norms. Child Abuse and Neglect 2005; 29: 384-412.

5. Hamby SL, Finkelhor D, Ormand R, Turner H. The Juvenile Victimisation Questionnaire (JVQ): Administration and Scoring Manual. Durham.NH: Crimes against Children Research Center, 2004.

6. Ministry of Education, Sri Lanka. General circular No. 2001/ 11.30.03.2001.

7. Child Welfare Information Gateway. www.childwelfare.gov/ pubs/factsheets/long_term_consequences.cfm.

8. Perry BD. The neurodevelopmental impact of violence in childhood. Texbook of Forensic Psychiatry. Boston: American Psychiatric press, 2001: 221-38.

9. Felitti VJ. Relationship of childhood abuse and household dysfunction to many of the leading causes of death in adults. The Adverse Childhood Experiences (ACE) study. American Journal of Preventative Medicine 1998; 14: 245-58. 